\title{
Solvothermal Synthesis of Copper Indium Diselenide in Toluene
}

\author{
Juyeon Chang, Jae Eok Han, and Duk-Young Jung*
Department of Chemistry, Institute of Basic Sciences and Sungkyunkwan Advanced Institute of Nanotechnology, Sungkyunkwan University, Suwon 440-746, Korea. *E-mail: dyjung@skku.edu Received October 28, 2010, Accepted November 24, 2010

\begin{abstract}
Polycrystalline CuInSe $\mathrm{C}_{2}$ (CIS) was synthesized through solvothermal reactions in toluene with selected alkyl amines as complexing agents. The alkyl amines were used as reducing agent of selenium and catalytic ligands, enhancing the formation of CIS compounds in the colloidal solution. Toluene does not contribute the syntheses directly but minimizes the amounts of amines required for single phase CIS. We systematically studied the reactivity of amine compounds for the solovothermal syntheses, determined critical concentration of amine and the shortest reaction time. Crystallinity, morphology, chemical composition, and band gap of the prepared $\mathrm{CuInSe} \mathrm{I}_{2}$ were respectively measured by X-ray diffraction, scanning electron microscopy, inductively coupled plasma atomic emission spectroscopy and UV-vis spectroscopy.
\end{abstract}

Key Words: Metal chalcogenides, Semiconductors, Solvothermal synthesis

\section{Introduction}

While CuInSe $\mathrm{S}_{2}$ (CIS) and related quaternary compounds have emerged as promising photon absorber materials for low-cost and high-efficiency thin-film solar cells, ${ }^{1-3}$ the expensive vacuum-based processes of $\mathrm{CuInSe}_{2}$ thin films hamper economic fabrication. Nanoparticle-based solution deposition would be potentially one of the candidates thanks to the reliable low-cost process, which typically comprises three stages: nanoparticle syntheses, deposition at low temperature, and annealing at a higher temperature. ${ }^{1,3}$

Several synthetic methods of CIS nanoparticles have been reported, for instance, including colloidal, ${ }^{1,4,5}$ sonochemical, ${ }^{6}$ microwaves, ${ }^{7,8}$ mechanochemical, ${ }^{9,10}$ and solvothermal methods. ${ }^{11-14}$ Although Qian's group reported the synthesis of $\mathrm{CuInSe}_{2}$ nanoclusters by solvothermal reactions of copper and indium salts with elemental selenium, ${ }^{13,14}$ we had only scant data limited to two amine solvents. Since neat amines are strong bases and also hazardous as reaction media, we usually encounter laboratory safety issue during the syntheses and recycle of wastes after solvothermal reactions.

Here we report several amine compounds in order to prepare CIS compounds and present an improved solvothermal synthesis that employs toluene as a less hazardous and recyclable reaction media. Several experimental parameters were investigated to optimize reaction conditions, including metal-amine chelate effect, concentration of alkyl amines and reaction time.

\section{Experimental Details}

Copper(II) chloride dihydrate (97\%), indium(III) chloride (98\%), selenium powder $(99.5 \%)$, toluene anhydrous $(99.8 \%)$, diethylamine (99.5\%), ethylenediamine (99.5\%), diethylenetriamine $(99 \%)$, triethylenetetramine $(60 \%)$, and hexamethylenetetramine (99\%) were used as received from Aldrich without further purification.

Table 1. Physical properties of selected alkyl amines

\begin{tabular}{|c|c|c|c|c|c|}
\hline & Diethylamine & Ethylenediamine & Diethylenetriamine & Triethylenetetramine & $\begin{array}{l}\text { Hexamethylene- } \\
\text { tetramine }\end{array}$ \\
\hline \multicolumn{6}{|l|}{ structure } \\
\hline phase & liquid & liquid & liquid & liquid & solid \\
\hline $\mathrm{bp}\left({ }^{\circ} \mathrm{C}\right)$ & $55^{\circ} \mathrm{C}$ & $118^{\circ} \mathrm{C}$ & $199-209{ }^{\circ} \mathrm{C}$ & $266^{\circ} \mathrm{C}$ & - \\
\hline $\mathrm{mp}\left({ }^{\circ} \mathrm{C}\right)$ & $-50{ }^{\circ} \mathrm{C}$ & $9{ }^{\circ} \mathrm{C}$ & $-35^{\circ} \mathrm{C}$ & $12{ }^{\circ} \mathrm{C}$ & $280^{\circ} \mathrm{C}$ (sublime) \\
\hline solubility in toluene & miscible & miscible & miscible & miscible & insoluble \\
\hline amine groups $^{a}$ & $1 * 2$ & $2 * 1$ & $2 * 1^{\prime}+1 * 2{ }^{\prime}$ & $2 * 1^{\prime}+2 * 2^{\prime}$ & $4 * 3$ \\
\hline 5-membered ring ${ }^{b}$ & - & 1 (monomer0)/2 (dimer) & 2 & 2 & - \\
\hline stability constant $^{c}$ & - & 10.7 (monomer)/9.3 (dimer) & 16.0 & 20.5 & - \\
\hline $\begin{array}{l}\text { optimized conc. } \\
\text { CIS product purity }\end{array}$ & $\begin{array}{c}\text { neat } \\
\text { single phase }\end{array}$ & $\begin{array}{c}>0.21 \mathrm{M} \\
\text { single phase }\end{array}$ & $\begin{array}{l}\text { not available } \\
\text { CuSe impurity }\end{array}$ & $\begin{array}{c}0.09 \mathrm{M} \\
\text { single phase }\end{array}$ & $\begin{array}{l}\text { not available } \\
\text { CuSe impurity }\end{array}$ \\
\hline
\end{tabular}

${ }^{a}$ number and degree of amine functional group in molecule -1';primary, $2^{\prime}$; secondary, 3 '; tertiary. ${ }^{b}$ number and degree of cyclic five-membered ring by bidentate amine ligands. ${ }^{c}$ reference 17. 
In a typical procedure, $0.082 \mathrm{~g} \mathrm{Se}(1.04 \mathrm{mmol}), 0.088 \mathrm{~g} \mathrm{CuCl}_{2}$. $2 \mathrm{H}_{2} \mathrm{O}(0.516 \mathrm{mmol})$ and $0.114 \mathrm{~g} \mathrm{InCl}_{3}(0.516 \mathrm{mmol})$ were mixed with $17 \mathrm{~mL}$ toluene in a $20 \mathrm{~mL}$ Teflon vessel targeting a stoichiometric composition of $\mathrm{Cu}: \mathrm{In}: \mathrm{Se}=1: 1: 2$. Alkyl amine was then added in ratios to copper between 0 and 7 . The autoclave was then tightly closed and maintained at $180{ }^{\circ} \mathrm{C}$ in a convection oven. After reaction, the autoclave was cooled to room temperature. The precipitate was filtered and washed with distilled water and ethanol several times. The final product was dried at $60{ }^{\circ} \mathrm{C}$ for 4 hours.

The formation of the $\mathrm{CuInSe}_{2}$ product was influenced by the choice of alkyl amine: diethylamine, ethylenediamine, diethylenetriamine, triethylenetetramine, and hexamethylenetetramine, whose physical properties are summarized in Table 1, possessing different number of amine functional groups in each molecule. At room temperature, first four amines are liquid and freely miscible with toluene. Hexamethylenetetramine is solid and insoluble in toluene.

$\mathrm{X}$-ray diffraction (XRD) was measured by a Rigaku D/MAX2000 Ultima, at $40 \mathrm{kV}$ and $30 \mathrm{~mA}$ with $\mathrm{Cu} \mathrm{K \alpha}$ radiation $(\lambda=$ $0.15418 \mathrm{~nm}$ ). Scanning electron microscopy (SEM) and energy dispersive spectroscopy (EDS) were performed with a Philips XL30 ESEM operating at $30 \mathrm{kV}$, equipped with EDAX Phoenix. Inductively coupled plasma atomic emission spectroscopy (ICPAES) analysis was carried out by a SHIMADZU ICPS-1000IV. UV-vis absorption spectra were collected on a Varian Cary 5000 .

\section{Results and Discussion}

The amount of alkyl amine added in the solvothermal reaction strongly influenced the formation of $\mathrm{CuInSe}_{2}$ phase. Figure 1 shows the XRD spectra of the CIS products prepared in diethylamine-toluene at $180{ }^{\circ} \mathrm{C}$ for 48 hours. When only toluene was used as the reaction medium, mixture of reduced $\mathrm{CuCl}$ (JCPDS, PDF \#06-0344) and unreacted Se(PDF \#06-0362) were produced, implying that amine is indispensible for CIS synthesis. In $0.15 \mathrm{M}$ diethylamine (amine/copper $=5$ ) solution, on the other

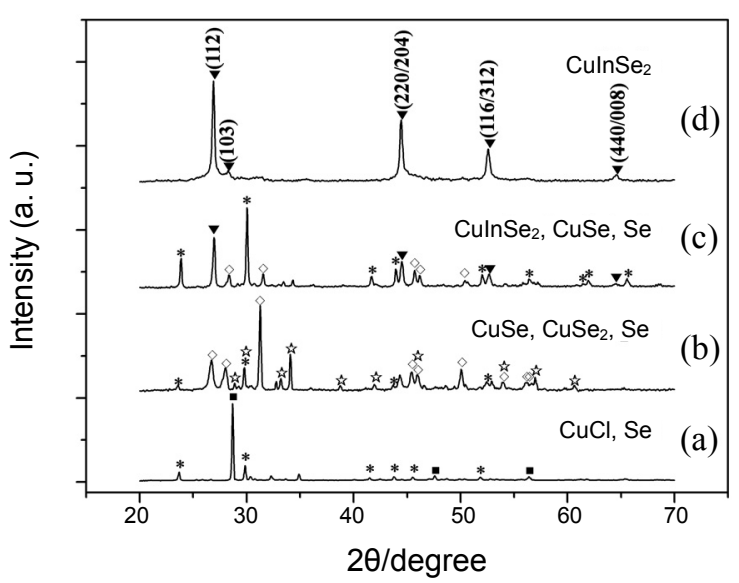

Figure 1. XRD spectra of the diethylamine samples prepared for $48 \mathrm{hrs}$ in (a) $0 \mathrm{M}$, (b) $0.15 \mathrm{M}$, (c) $0.21 \mathrm{M}$ and (d) neat diethylamine solvent. Selected peaks are marked for comparison: $(\nabla) \mathrm{CuInSe}_{2},(*) \mathrm{Se},(\diamond)$ $\mathrm{CuSe},\left(\right.$ 污) $\mathrm{CuSe}_{2}$, and (匹) $\mathrm{CuCl}$. hand, some Se were reduced to $\mathrm{Se}^{2-}$, and reacted with $\mathrm{Cu}^{2+}$ to mainly form CuSe phase (PDF \#06-0427) along with $\mathrm{CuSe}_{2}$ (PDF \#19-0400) and Se. CuInSe 2 phase was observed when diethylamine increased to $0.21 \mathrm{M}$ or higher concentration, but single phase CuInSe ${ }_{2}$ was obtained from only neat diethylamine solvent. Three strongest diffraction peaks at $26.6^{\circ}, 44.2^{\circ}$, and $52.3^{\circ}$ shown in Figure 1d were indexed to (112), (220/204), and (116/312) reflections of the chalcopyrite structure, in which the observed peaks match with the reference JCPD data (PDF \#40-1487).

The XRD spectra of the CIS products prepared in ethylenediamine-toluene at $180{ }^{\circ} \mathrm{C}$ for 24 and 48 hours are shown in Figure 2. Ethylenediamine obviously assisted the CIS synthesis in low concentration below $0.15 \mathrm{M}$. The reactivity could be ascribed to two primary amine groups of ethylenediamine, which are stronger Lewis base compared to diethylamine with one secondary amine. We also observed the dependence of solvothermal reaction time in $0.15 \mathrm{M}$ ethylenediamine case, the reaction of 24 hours gave a mixture of $\mathrm{CuInSe}_{2}, \mathrm{CuSe}$, and $\mathrm{Se}$ as shown in Figure 2a, however, when the reaction time was extended to 48 hours, those phases disappeared and the crystallization of the $\mathrm{CuInSe}$ phase were remarkably enhanced. Single phase $\mathrm{CuInSe}_{2}$ was obtained when $0.21 \mathrm{M}$ or higher concentration of ethylenediamine solution was used for 24 hour reactions.

Diethylamine and ethylenediamine have been mostly used for solvothermal syntheses of CIS at above $180{ }^{\circ} \mathrm{C}$ for several hours. ${ }^{13-16}$ In the present study, we note to utilize the new reaction media with minimum amount of ethylenediamine in toluene for solvothermal syntheses, reduced amine concentration less than $0.21 \mathrm{M}$ for single phase CIS. The reaction media could be recovered by filtration and used for several times, which shows advantage for green chemistry and low cost production of CIS phase. The present study also confirmed the previous report that diethylamine needs longer reaction time to prepare CIS phase than ethylenediamine. ${ }^{14}$ The successful synthesis of CIS in the smaller concentration of ethylenediamine is attributed to primary amine groups rather than a secondary one in diethylamine, which could be extended to other amine compounds

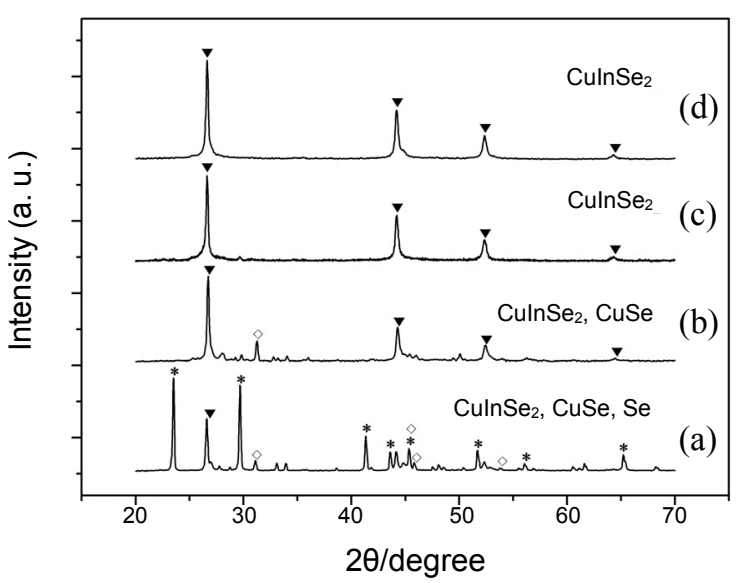

Figure 2. XRD spectra of the ethylenediamine samples prepared in $0.15 \mathrm{M}$ for (a) $24 \mathrm{hrs}$ and (b) $48 \mathrm{hrs,} \mathrm{(c)} 0.21 \mathrm{M}$, and (d) neat ethylenediamine solvent for $24 \mathrm{hrs}$. Selected peaks are marked for comparison: $(\boldsymbol{\nabla}) \mathrm{CuInSe}_{2},(*) \mathrm{Se}$, and $(\diamond) \mathrm{CuSe}$. 


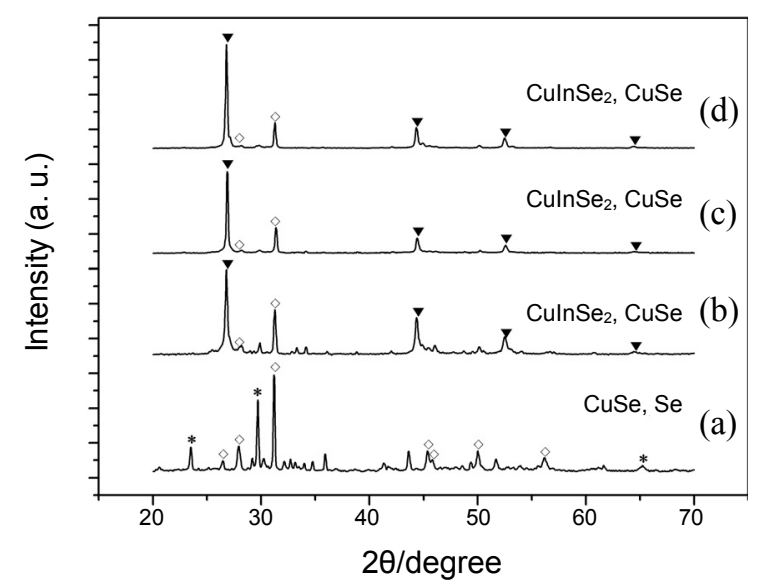

Figure 3. XRD spectra of the diethylenetriamine samples prepared for $24 \mathrm{hrs}$ in (a) $0.03 \mathrm{M}$, (b) $0.09 \mathrm{M}$, (c) $0.15 \mathrm{M}$ and (d) neat diethylenetriamine solvent. Selected peaks are marked for comparison: $(\boldsymbol{\nabla}) \mathrm{CuInSe}_{2}$, $(*) \mathrm{Se}$, and $(\diamond) \mathrm{CuSe}$.

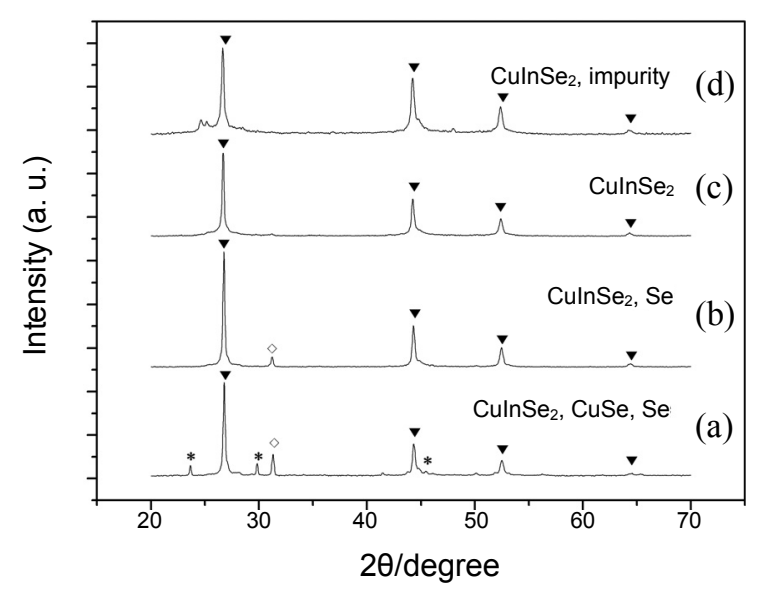

Figure 4. XRD spectra of the triethylenetetramine samples prepared in (a) $0.03 \mathrm{M}, 0.09 \mathrm{M}$ for (b) $24 \mathrm{hrs}$ and (c) $48 \mathrm{hrs}$, and (d) neat triethylenetetramine solvent for $24 \mathrm{hrs}$. Selected peaks are marked for comparison: $(\boldsymbol{\nabla}) \mathrm{CIS},(*) \mathrm{Se}$, and $(\diamond) \mathrm{CuSe}$.

\section{(vide infra).}

Figure 3 presents the XRD spectra of the products prepared in diethylenetriamine for 24 hours. Since diethylenetriamine has two primary and one secondary amine groups more than diethylamine and ethylenediamine, CIS phase could be produced with a relatively small concentration about $0.09 \mathrm{M}$ and for shorter reaction time of 24 hours. However, the product contained a small quantity not negligible amount of CuSe phase even in higher concentration of diethylenetriamine, which is not applicable to synthesis for single phase CIS.

Figure 4 presents the XRD spectra of the products prepared in triethylenetetramine-toluene at $180{ }^{\circ} \mathrm{C}$ for 24 and 48 hours. Triethylenetetramine containing two primary and two secondary amines, improved formation of $\mathrm{CuInSe}_{2}$ with the smallest concentration of alkyl amine of $0.03 \mathrm{M}$, amine/copper $=1$. The $0.09 \mathrm{M}$ amine sample for 24 hours involved a small amount of $\mathrm{CuSe}$ and Se side-products, which disappeared in 48 hours reaction. The lattice constants for the prepared $\mathrm{CuInSe}_{2}$ are refined

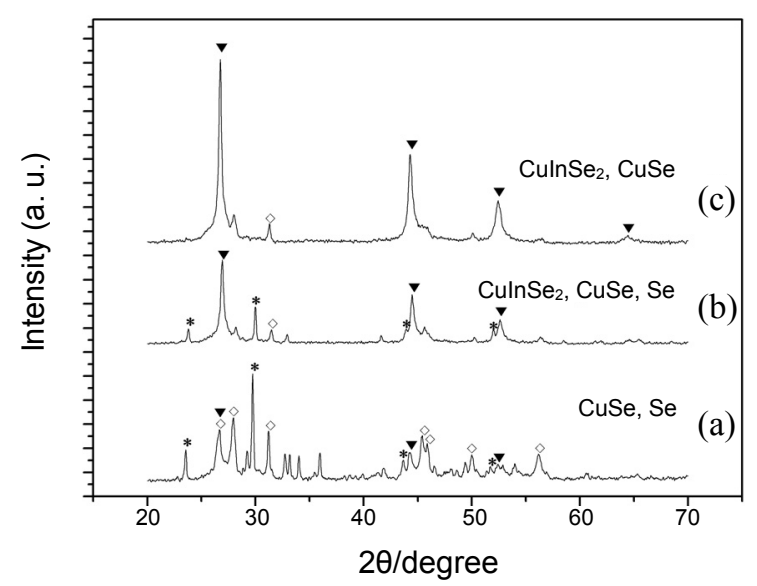

Figure 5. XRD spectra of the hexamethylenetetramine samples prepared for $48 \mathrm{hrs}$ in (a) $0.03 \mathrm{M}$, (b) $0.09 \mathrm{M}$, and (c) $0.15 \mathrm{M}$ hexamethylenetetramine solvent. Selected peaks are marked for comparison: $(\boldsymbol{\nabla})$ $\mathrm{CIS},(*) \mathrm{Se}$, and $(\diamond) \mathrm{CuSe}$.

by the least square method, $a=0.579 \mathrm{~nm}$ and $c=1.160 \mathrm{~nm}$, which are in good agreement with the reference data (PDF \#40-1487, $a=0.578 \mathrm{~nm}$ and $c=1.162 \mathrm{~nm}$ ). ${ }^{17}$ Surprisingly, the neat triethylenetetramine gave unknown impurity phase which presented the XRD peaks at around $26.6^{\circ}$, which do not correspond to the JCPDS data for $\mathrm{Cu}-\mathrm{Se}$ compounds. Thus there is a narrow amine concentration range for the successful synthesis for single phase CIS, the high concentration of amine rather could provide side-products in certain experimental conditions.

Figure 5 shows the XRD spectra of CIS prepared in hexamethylenetetramine-toluene at $180^{\circ} \mathrm{C}$ for 48 hours. The experiment using neat hexamethylenetetramine could not be performed because the amine is solid at room temperature. The CIS product prepared in $0.09 \mathrm{M}$ hexamethylenetetramine solution contained impurities of $\mathrm{CuSe}$ and Se together with $\mathrm{CuInSe}_{2}$, although single phase CIS was produced by triethylenetetramine under similar conditions. The side-product of CuSe appears even when the concentration of hexamethylenetetramine was increased up to $0.15 \mathrm{M}$, presumably attributed to difference in degree of amine groups and their basicity of above two amines. Hexamethylenetetramine is a cyclic amine compound containing four tertiary amine groups, while triethylenetetramine is an aliphatic amine containing two primary and two secondary amine groups with stronger capability of ligand-metal coordination as summarized in Table 1.

The added amines play an important role in the solvothermal synthesis of CIS, especially the purity of the products. ${ }^{14}$ As both temperature and pressure of the reaction increase, $\mathrm{Se}$ is reduced to $\mathrm{Se}^{2-}$, and $\mathrm{Cu}^{2+}$ and $\mathrm{In}^{3+}$ form stable metal-chelate complexes, which prevent the formation of binary metal chalcogenides. ${ }^{14}$ The metal-amine complexes react with $\mathrm{Se}^{2-}$ to form $\mathrm{CuInSe}$. Therefore, the higher stability constants of the $\mathrm{Cu}^{2+}-$ amine chelates are able to enhance the CIS formation. In the present study, the high stability constants of the $\mathrm{Cu}^{2+}$-amine complexes are ranked as following; triethylenetetramine (log $\mathrm{K}=20.5$ ), diethylenetriamine (16.0) and ethylenediamine (10.7 and 9.3 for monomer and dimer cases, respectively) ${ }^{18}$ We suggest that the minimal amine concentrations for CIS phase depend 


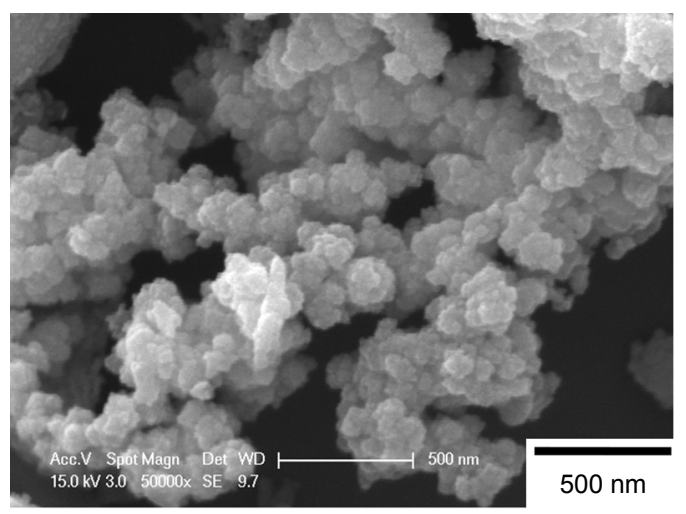

Figure 6. SEM image of the triethylenetetramine sample $(0.09 \mathrm{M})$ prepared at $180{ }^{\circ} \mathrm{C}$ for $48 \mathrm{hrs}$.

(a)

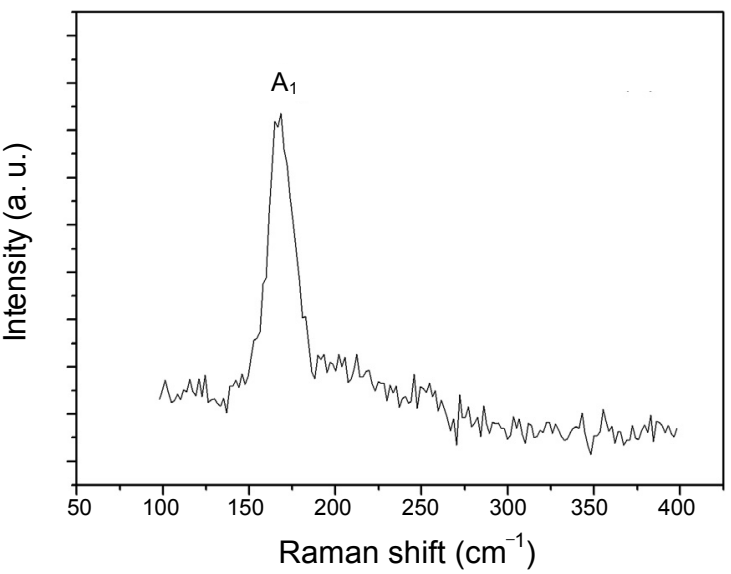

(b)

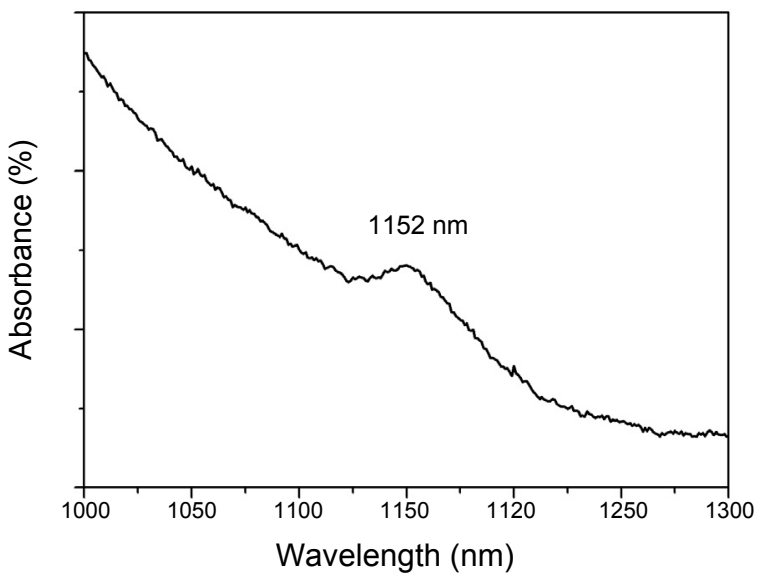

Figure 7. (a) Raman and (b) UV-vis absorption spectra of the triethylenetetramine sample $(0.09 \mathrm{M})$ prepared at $180{ }^{\circ} \mathrm{C}$ for $48 \mathrm{hrs}$.

on the stability constant of amines. However, the formation of $\mathrm{CuSe}$ phase is likely to be independent of the correlation between the number of amine groups and stability constants. At least, we could expect that the tertiary amine groups are not strong enough to give single phase CIS as shown in the case of hexamethylenetetramine.

The SEM images of the CIS product prepared in triethylenetetramine-toluene are shown in Figure 6. The sample was com- posed of an aggregate of irregularly shaped particles. The average size of particles was $67 \mathrm{~nm}$. The crystal size calculated by the Scherrer equation from the width of the XRD diffraction peak of the (112) plane was $33 \mathrm{~nm}$. The average composition of the product determined by EDX was $\mathrm{Cu}_{1.0} \mathrm{In}_{0.98} \mathrm{Se}_{2.2}$, which was also confirmed by ICP-AES giving the ratio of $\mathrm{Cu}$ :In : Se as $1.1: 1.0: 2.1$.

Typical Raman and UV-vis absorption spectra of the $\mathrm{CuInSe}_{2}$ sample prepared in triethylenetetramine-toluene are presented in Figure 7. The Raman spectra exhibit a strong characteristic A1 mode peak at $172 \mathrm{~cm}^{-1}$, generally observed from chalcopyrite compounds. ${ }^{19}$ The most intense peak resulted from the motion of Se atoms of $\mathrm{CuInSe}_{2}$ and distinguishes the chalcopyrite phase from the sphalerite phase $\left.\left(182 \mathrm{~cm}^{-1}\right)\right)^{20}$ There is no other impurity phase, such as $\mathrm{Cu}_{\mathrm{x}} \mathrm{Se}\left(258 \mathrm{~cm}^{-1}\right),{ }^{21}$ in the Raman spectrum, indicating that a high purity $\mathrm{CuInSe} 2$ chalcopyrite compound was synthesized. The UV-vis absorption spectra were taken for the sample in absolute ethanol. The spectra of the samples have peak maxima at $1152 \mathrm{~nm}$, which is a smaller wavelength than that of bulk $\mathrm{CuInSe}{ }_{2}{ }^{22}$

\section{Conclusion}

The single phase $\mathrm{CuInSe} \mathrm{I}_{2}$ was successfully prepared via an amine-assisted solvothermal process using toluene as reaction media. The formation of CIS could be systematically studied by amine concentration and reaction time. The best synthetic condition of single phase CIS is closely related to the degree, the number and the stability constant of amine added, which is only $0.09 \mathrm{M}$ concentration of triethylenetetramine for 48 hours at $180{ }^{\circ} \mathrm{C}$. We expend the CIS synthesis to other amine compounds to investigate the predominant parameter to determine the purity of CIS phase and the minimal concentrations of added amines. This synthetic method also opened a potential application of CIS solar cell devices, such as fabrication of sputtering targets and CIS nano-ink for coating processes.

Acknowledgments. This research was supported by Industrial Strategic Technology Development program (10033492, KEIT), the Korea Research Foundation Grant funded by the Korean government (KRF-2008-005-J00702, MOEHRD), the National Research Laboratory Program of Korea Science and Engineering Foundation (ROA-2007-000-10020-0), Research Center of Break-through Technology Program (20093021010030), and Center for Human Interface Nano Technology (2010-0015037, HINT).

\section{References}

1. Schulz, D. L.; Curtis, C. J.; Flitton, R. A.; Wiesner, H.; Keane, J.; Matson, R. J.; Jones, K. M.; Parilla, P. A.; Noufi, R.; Ginley, D. S. J. Electron. Mater. 1998, 27, 433.

2. Repins, I.; Contreras, M. A.; Egaas, B.; DeHart, C.; Scharf, J.; Perkins, C. L.; To, B.; Noufi, R. Prog. Photovoltaics Res. Appl. 2008, 16, 235 .

3. Kaelin, M.; Rudmann, D.; Tiwari, A. N. Sol. Energy 2004, 77, 749 .

4. Koo, B.; Patel, R. N.; Korgel, B. A. J. Am. Chem. Soc. 2009, 131, 3134. 
5. Guo, Q.; Kim, S. J.; Kar, M.; Shafarman, W. N.; Birkmire, R. W.; Stach, E. A.; Agrawal, R.; Hillhouse, H. W. Nano Lett. 2008, 8, 2982.

6. Jung, D.-Y.; Han, J. E.; Chang, J. 2009, PCT/KR2008/003421.

7. Grisaru, H.; Palchik, O.; Gedanken, A.; Palchik, V.; Slifkin, M. A.; Weiss, A. M. Inorg. Chem. 2003, 42, 7148.

8. Landry, C. C.; Lockwood, J.; Barron, A. R. Chem. Mater. 1995 , 7, 699 .

9. Chung, J.; Kim, S.-J. Bull. Korean Chem. Soc. 2010, 31, 2695.

10. Wada, T.; Kinoshita, H. J. Phys. Chem. Solids 2005, 66, 1987.

11. Xu, J.; Lee, C.-S.; Tang, Y.-B.; Chen, X.; Chen, Z.-H.; Zhang, W. -J.; Lee, S. -T.; Zhang, W.; Yang, Z. ACS Nano 2010, 4, 1845.

12. Yang, Y.-H.; Chen, Y.-T. J. Phys. Chem. B 2006, 110, 17370.

13. Jiang, Y.; Wu, Y.; Mo, X.; Yu, W.; Xie, Y.; Qian, Y. Inorg. Chem.
2000, 39, 2964.

14. Li, B.; Xie, Y.; Huang, J.; Qian, Y. Adv. Mater. 1999, 11, 1456.

15. Xiao, J.; Xie, Y.; Xiong, Y.; Tang, R.; Qian, Y. J. Mater. Chem. $2001,11,1417$.

16. Chen, H.; Yu, S.-M.; Shin, D.-W.; Yoo, J.-B. Nanoscale Res. Lett. 2010, 5, 217.

17. Suri, D. K.; Nagpal, K. C.; Chadha, G. K. J. Appl. Cryst. 1989, 22, 578.

18. Martell, A. E.; Chaberek, S. Anal. Chem. 1954, 26, 1692.

19. Rincón, C.; Ramírez, F. J. J. Appl. Phys. 1992, 72, 4321.

20. Shirakata, S.; Murakami, T.; Kariya, T.; Isomura, S. Jpn. J. Appl. Phys., Part 1 1996, 35, 191.

21. Wan, L.; Cao, Y.; Wang, D. J. Mater. Res. 2009, 24, 2294.

22. Kavcar, N. Sol. Energy Mater. Sol. Cells 1998, 52, 183. 